\title{
Essentializing Inferences
}

\author{
Katherine Ritchie \\ University of California, Irvine \\ Penultimate Draft \\ Final version forthcoming in Mind \& Language
}

\begin{abstract}
Predicate nominals (e.g., 'is a female') seem to label or categorize their subjects, while their predicate adjective correlates (e.g, 'is female') merely attribute a property. Further, predicate nominals elicit essentializing inferential judgments about inductive potential as well as stable explanatory membership. Semantic data and research from developmental and cognitive psychology support that this distinction is robust and productive. I argue that while the difference between predicate nominals and predicate adjectives is elided by standard semantic theories, it ought not be. I then develop and defend a psychologically motivated semantic account that takes predicate nominals to involve attributing kind membership and to trigger a presupposition that underpins our essentialist judgments.
\end{abstract}

Key Words: predicate nominals, predicate adjectives, nouns, essentialism, kinds, presupposition

"Probably a crab would be filled with a sense of personal outrage if it could hear us class it without ado or apology as a crustacean, and thus dispose of it, 'I am no such thing,' it would say; 'I am MYSELF, MYSELF alone.”

—William James (1902/2012: 6)

Essentialist thinking involves categorizing entities into kinds which are taken to have shared underlying natures. A large body of existing research shows that the words we use affect the degree to which we essentialize. For instance, consider the difference between the sentences in the following pairs.

1. a. Anna is female.

b. Anna is a female.

2. a. Dante is queer.

b. Dante is a queer.

3. a. Lorraine is blonde.

b. Lorraine is a blonde.

4. a. Frank is Black.

b. Frank is a Black. 
The $b$ sentences, which include predicate nominals (e.g., is a female), seem to classify or label the subject. They convey that that is what the person is. Further, predicate nominals elicit a form of essentialist thinking about a group or kind. For instance $4 \mathrm{~b}$ might lead one to think that there are other shared features or stereotypes that can explain the behavior or attitudes of Black people. It might reinforce the view that there is an underlying nature that Black people share.

In contrast the $a$ sentences, which involve the same expression as a predicate adjective (e.g., is female), do not seem to classify the subject into a group or social category. Rather, they merely attribute some property to the subject. They fail to elicit the sort of stereotypical generalizations the $b$ sentences do. For instance, $3 \mathrm{a}$ only reports on Lorraine's hair color, while $3 \mathrm{~b}$ implies something further (e.g., about her being unintelligent or glamorous). ${ }^{1}$

Much of the work on essentialism has focused on its psychological manifestations and its normative and socio-political import. Here I consider what psychological essentialism requires of semantics. As anyone familiar with first-order logic will know, predicates in nominal and adjectival form are treated as having the same logical form. For instance, 1a and $1 \mathrm{~b}$ could both be translated as Fa. Standard formal semantic treatments also treat predicate nominals and adjectives as equivalent (e.g., Heim \& Kratzer, 1998). Using a range of linguistic and psychological data as support, I argue that a semantic theory ought to draw a distinction between predicate nominals and predicate adjectives. I then develop and defend a semantic account that explains the differences between them in a linguistically and psychologically motivated way.

In what follows I begin by canvassing data from psychology and semantics to support that there is a robust distinction between predicate nominals and predicate adjectives $(\llbracket I)$. I show that the distinction is elided in standard semantic theories and argue against two non-semantic accounts ( $(I I I)$.

\footnotetext{
1 Pluralizing the subject expression affects the way the distinction is expressed, but notice that the difference in inferential judgments is retained.

a. Elijah and Krista are Black.

b. Elijah and Krista are Blacks.
} 
I then sketch and defend a semantic account on which predicate nominals, but not predicate adjectives, attribute kind membership and trigger the presupposition that there is an inductively potent kind with stable and explanatory membership ( $(I I I)$.

Three notes before proceeding_one definitional and two clarificatory. First, essentialism has been understood in a multitude of ways in philosophy and psychology. Here I am focused on representational or psychological essentialism. I follow the psychologist Susan Gelman in taking representational essentialism to involve two related components—a kind component and an essence component. The kind component is "that people treat certain categories as richly structured 'kinds' with clusters of correlated properties" (2004: 408). Natural categories (e.g., hydrogen, elephants), social categories (e.g., Black people, doctors), and artifact categories (e.g., chairs, computers) can all be treated as kinds (Markman, 1989; Gelman, 2003; Noyes and Dunham, 2019).

The essence component is that people represent categories as having an underlying essence that is responsible for observable properties but which "cannot be observed directly" (Gelman, 2004: 208.).2 Much of the psychological research on essence has focused on natural categories, particularly animal kinds. The dominant view coming from this research is that essences are represented as causal. Underlying essences are taken to cause superficial features (see Gelman, 2003; Keil, 1989; Medin \& Ortony, 1989). Social categories like race and gender have been found to be represented as having causal biological essences (Rothbart \& Taylor, 1992). On another view, essences are taken to be values or ideals that are realized in observable features or actions (Newman and Knobe, 2019). Research has found that some other social categories (e.g., scientists, mothers) and aesthetic kinds (e.g., rock music, poems) are represented as having these evaluative essences (Del Pinal and Reuter, 2017; Leslie, 2015; Newman and Knobe, 2019). On a third view, essences are taken to be teleological (Rose \& Nichols, 2020). Evidence supports that artifacts as well as other kinds are

\footnotetext{
2 The assumption that kinds have underlying essences might be unconscious or implicit. For instance, Leslie emphasizes that we might "rarely, if ever, explicitly entertain thoughts about [essence] as such; rather, [our essentialist] beliefs are tacit or implicit, though they are frequently manifested in a number of explicit ways" (2013: 110).
} 
represented as having functional or teleological essences (Rose \& Nichols, 2020). Here I argue that it is the kind component that is key to understanding the different semantic contributions of nouns and adjectives. The account I offer is compatible with various views on the nature of representations of essence, while capturing the commonalities that arise when nouns are used.

Now for two brief clarificatory remarks. First, my focus here is on nouns for social categories as these are of particular interest given their normative significance. The semantic view I offer in the final section is one I take to be generalizable to other nouns as well. I return to this observation in $\int I I I$.

Finally, I want to make clear that my aim here is not to inquire into whether the inferences drawn from predicate nominals are good. The inferences drawn are often pernicious, inductively weak, invalid, or unsound. I grant that the sorts of inferences triggered by the $b$ sentences considered above are overwhelmingly ones that we ought not draw. My focus here is on what the differences in meaning and inferential potential in pairs like 1-4 require from a semantic theory. Without further ado let's turn to data to support that there is a distinction between predicate nominals and adjectives.

\section{Data to Motivate the Distinction}

To show that the pattern we saw in 1-4 is robust, I offer further linguistic data and experimental support from cognitive and developmental psychology. ${ }^{3}$ We begin with evidence from psychology. Then we turn to data based on contrast and focus, conversational exchanges, and anaphora.

\section{Ia. Psychological Evidence}

Experiments in cognitive and developmental psychology show that expression type can affect essentialist thinking. When labeling with nouns, it is hypothesized that "the mere act of

\footnotetext{
${ }^{3}$ In Ritchie (forthcoming), I consider the upshot of some of the data presented here for linguistically oriented ameliorative social-political projects.
} 
categorization triggers processes involved in the construction of social stereotypes" (Bigler \& Liben, 2007: 164). Labeling and categorizing also have significant effects on how we conceptualize and on the inferences we draw. Gelman argues "language that is used to express membership in a category can influence children's judgments about that category" and that "[c]ount nouns imply that a category is relatively more stable and consistent over time and contexts than adjectives or verbal phrases" (2004: 407). She concludes that while representational essentialism is likely hardwired into human psychology, labeling with nouns can further promote essentialist thinking.

Both children and adults have been found to draw more substantial inferences and take a predicated characteristic to be more persistent, stable, and explanatory when a noun rather than an adjective or other VP constructions is used (Gelman \& Markman, 1987; Markman, 1989; Gelman \& Coley, 1990; Waxman, 1990; Jaswal \& Markman, 2002; Graham et al., 2004; Walton \& Banaji, 2004; for data from languages other than English see, Carnaghi et al., 2008; Graf et al., 2013).

To test whether predicate nominals themselves rather than particular lexical items (e.g., blonde, tiger) are responsible for differences in inferential judgments Gelman and Heyman (1999) designed an experiment using novel predicate nominals. They tested whether 5- and 7-year-olds had different judgments about the stability of a property, past and future behavior, and counterfactual behavior when offered sentences like those in 5 .

5. a. Rose eats carrots whenever she can.

b. Rose is a carrot-eater.

They found that children judged that characteristics were more persistent and stable when predicate nominals were used as in $5 \mathrm{~b}$. Since the nouns in the study were not previously lexicalized they conclude that "children were not retrieving rote meanings, but rather made use of a general rule that they applied to these novel noun phrases” (Gelman \& Heyman, 1999: 491).

While these studies go some way towards showing that nouns as a lexical category elicit stronger persistence and stability judgments than verb phrases or adjectives, there are several reasons 
we might seek additional evidence. First, while the sentence in $5 \mathrm{~b}$ does include a novel nominal, it is formed from familiar words modified with the -er suffix. Using completely novel expressions will eliminate any potential confounds coming from participants' beliefs about, say, foods or preferences. Second, the sentence in 5a has a complex VP that is fairly weak. For instance, it might be true that one goes scuba diving whenever they can, without it being true that they do so frequently.

In order to gain more definitive support for a robust and productive distinction between predicate nominals and adjectives, I ran a preregistered study with wholly novel predicate nominals and predicate adjectives. ${ }^{4}$ Two hundred and ninety-five participants were recruited through Amazon Mechanical Turk and tested through Qualtrics. Each participant was randomly assigned into one of two conditions: noun or adjective. They were asked to read a short story that began:

Rose lives in a community with other people. In that community people speak English, but they use some words that you've never heard before. One thing they say that is true about Rose is ...

In the adjective condition the story ended with $6 \mathrm{a}$, in the noun condition, with $6 \mathrm{~b}$.

6. a. Rose is dax.

b. Rose is a dax.

Participants were then asked to answer questions about how likely it was that Rose was dax / a dax two years ago, would be dax / a dax two years from now, and would have been dax / a dax had she had been raised in a different environment.

There were statistically significant results $(p<.05)$ for stability judgments about the past and future. Participants judgments were higher (i.e., they judged that it was more likely) in the noun than adjective conditions for both temporal judgment types. There was not a statistically significant

\footnotetext{
4 All study materials including a short overview of the purpose and results are available here: https://osf.io/7gtyq/? view only $=22 \mathrm{c} 35 \mathrm{~b} 55 \mathrm{~b} 4 \mathrm{ee} 4906 \mathrm{~b} 8084 \mathrm{~d} 4 \mathrm{e} 7 \mathrm{e} 373577$
} 
difference for counterfactual judgments, but there was a trend in the same direction. ${ }^{5}$ This study provides strong evidence that even completely novel nouns elicit stronger stability and persistence judgments than adjectives.

Experimental results show that a difference in lexical category affects people's judgments. It also supports that the differences we noticed between pairs like $1 \mathrm{a}$ and $1 \mathrm{~b}$ are widespread and that the phenomenon is productive. ${ }^{6}$

\section{Ib. Contrast and Focal Data}

Contrast and focus data provide further evidence for a robust difference between predicate adjectives and predict nominals. Consider the felicity differences between the sentence in $7 \mathrm{a}$ and those in $7 \mathrm{~b}$ and $7 \mathrm{c}$.

7. a. Meryl is blonde, but not a blonde.

b. Meryl is a blonde, and she isn't even blonde!

c. \#? Meryl is blonde, but not blonde.

d. \#? Meryl is a blonde, but not a blonde.

7a, which includes a predicate adjective followed by a predicate nominal, has a consistent interpretation. A felicitous interpretation is made even more salient when focus is put on the indefinite article. One natural interpretation involves saying of Meryl that she is flaxen-haired, but not, e.g., unintelligent, ditzy, or glamorous (Wierzbicka, 1986). Similarly, 7b might be interpreted as

\footnotetext{
5 Participants made judgments using a 7-point scale ranging from extremely unlikely (1) to extremely likely (7). For judgments about the past ratings were higher in the noun condition $(M=5.7, S D=1.2)$ than in the adjective condition $(M=5.3, S D=1.3), t(282)=2.6, p<.01$. For judgments about the future ratings were higher in the noun condition $(M$ $=5.9, S D=.9)$ than in the adjective condition $(M=5.6, S D=.9), t(282)=2.6, p=.01$. For judgments about counterfactuals there was no significant difference between ratings in the noun condition $(M=4.8, S D=1.6)$ and in the adjective condition $(M=4.5, S D=1.5), t(282)=1.5, p=.14$.

${ }^{6}$ Not all nouns promote essentialist thinking to the same degree. Research focused on causal essences has found that natural kinds and social kinds like gender categories tend to license strong inferences, while those for artifacts (e.g., chairs) license fewer (Gelman, 2003). Yet, when functional and evaluative properties are taken into consideration, artifacts also support robust inductive inference (Rose \& Nichols, 2020; Chaigneau \& Barsolou, 2008 for an overview). Ongoing research continues to explore the differences and commonalities in representations of categories across domains.
} 
expressing that while Meryl lacks the superficial feature of being flaxen-haired, nevertheless deep down she is has a blonde nature. In contrast, both $7 \mathrm{c}$ and $7 \mathrm{~d}$ sound straightforwardly contradictory. Focus as in 7c' and 7d' make the sentences somewhat better, although still less felicitous than 7a.

7c'. ?? Meryl is blonde, but not blonde.

$7 \mathrm{~d}$. ? Meryl is a blonde, but not a blonde.

While focus affects felicity judgments, the difference in whether an expression is used as an adjective or in a noun phrase also makes an important difference in felicity judgments. This provides evidence that nominal and adjectival forms express different contents.

For my purposes here what is important is that there is a difference between constructions of the form ' $A$ is $F$, but not an $F$ ' on the one hand and ' $A$ is $F$, but not $F$ ' or ' $A$ is an $F$, but not an $F$ on the other. While our judgments about what is conveyed and the degree to which a sentence is felicitous vary with choice of $F$, in general the former cases are substantially more felicitous than the latter. Further examples show that the pattern is not limited to blonde. Consider examples 8-11.

8. Dante is intellectual, but not an intellectual.

9. Charlotte is conservative, but not a conservative.

10. Roberto is Italian, but not an Italian.

11. Terry is queer, but not a queer.

In uttering 10, one might express that Roberto has Italian ancestry, but not Italian citizenship. Or they might be expressing that while Roberto is an Italian citizen, he fails to meet conditions for what it really means to be Italian given in terms of personality, style of dress, values, and so on. An utterance of 9 might express that Charlotte is conservative in some ways (perhaps in her beliefs about gender roles), but she is not correctly categorized as a member of the conservative party. Modifying any of $8-11$ to be of the form ' $A$ is $F$, but not $F$ or ' $A$ is an $F$, but not an $F$ makes the sentences significantly less felicitous, just as we saw for $7 \mathrm{c}$ and $7 \mathrm{~d}$.

\section{Ic. Conversational Exchanges}


Conversational exchanges offer further data to support a contrast between predicate adjectives and predicate nominals. Consider the exchange in 12.

12. A: Is Sodiq a queer?

B: Well, he is queer. (But I wouldn't say he is a queer.)

B hedges with her use of well, thereby avoiding an outright yes- or no-answer. If B were to agree categorically, it seems she would commit to something stronger than that Sodiq is queer, for instance that Sodiq's essence makes him queer or being queer defines who Sodiq is. If B were to give an explicit negative answer, she would commit to Sodiq not being queer. B's parenthetical is plausibly interpreted as a rejection of language that categorizes Sodiq or anyone else as a queer. It could also be interpreted as expressing that while B might classify some others as queers, she doesn't take Sodiq to meet the stereotypes or standard traits associated with the category. In contrast, the conversational pattern in 13 does not require hedging in order to avoid categorizing, essentializing, or negative generalizations.

13. A: Is Sodiq queer?

B: Yes, he is. ??(But I wouldn't say he is a queer.)

In fact, it would be quite odd to respond with "well, yes he is" It would also be strange for B to follow up with the same parenthetical as used in 12. Both of these features can be explained given that the issue of whether Sodiq is correctly categorized as a queer simply does not arise in 13. Different responses are appropriate to questions of the form 'Is $A$ an $F$ ?' and 'Is $A$ F?'

\section{Id. Anaphora}

Predicate adjectives and predicate nominals also differ in the ease with which they license plural anaphora. Consider the pair in 14.

14. a. Anna is female. They are nurturing and gentle.

b. Anna is a female. They are nurturing and gentle. 
The predicate nominal in $14 \mathrm{~b}$ easily licenses the use of the plural pronoun. They is naturally interpreted as equivalent to a bare plural use of females. In contrast, 14a does not easily license a kind-denoting use of the pronoun. While such an interpretation is possible in certain contexts, it is far more strained than in $14 \mathrm{~b}$.

The anaphora licensed by predicate nominals is of a piece with a more general pattern of nouns licensing plural anaphors. For example, Roberts (2005: 533) notes the acceptability of the 15 and 16:

15. Sam's dog got into my compost pile last night. They love rotten stuff.

16. Few linguists smoke. They know it causes cancer. (from Webber, 1978)

The uses of they in 15 and 16 are plausibly synonymous with dogs and linguists, respectively. This is the case even though the uses are not anaphoric on a bare plural or other construction that refers to the kind. As Roberts states "Apparently, mention of an instance of a kind or quantification over [members] of a kind are generally sufficient to make the kind itself salient" (ibid).

The data considered in sections Ia-1d support that there is a strong contrast between predicate nominals and predicate adjectives. They differ in whether they easily license anaphors, their felicity in contrastive claims, and so on. Predicate nominals categorize. They elicit essentialist inferences about further shared features and judgments that the categorization is stable and explanatory. In contrast, predicate adjectives seem to merely ascribe a property. Next I turn to what the distinction requires from a semantic theory.

\section{A Semantic Difference between $F$ and an F?}

While we saw that predicate adjectives and predicate nominals elicit different judgments about what is said and what is inferred, semanticists have treated them as equivalent (Montague, 1973; Partee, 2002/1986; Heim \& Kratzer, 1998; von Fintel \& Heim, 2001). For instance, in their seminal textbook, Heim and Kratzer state that "We will assume...that the indefinite article ' $a$ ' is vacuous 
when it occurs in predicate nominals such as 'a cat' in 'Kaline is a cat"' (1998: 61). They identify lexical entries of predicates and predicate nominals as in 17.

\section{7. $\llbracket$ a cat $\rrbracket=\llbracket c a t \rrbracket$}

It is standard for any predicate, whether in nominal or adjectival form, to be treated as function of type $<e, t>$. Even those who take some nouns to have non-predicative argument-type extensions (e.g., to be of type e), take predicate nominals to be of this predicate type, rather than, say, kindreferring expressions (e.g., Chierchia, 1998; Krifka et al., 1995; Quine, 1960; Partee, 2002/1986). For example, Partee states that "predicative indefinites like a man are always fully equivalent to the common noun" (2002/1986: 365, emphasis original).

In the context of more general theories of lexical categories, several theorists have developed accounts that posit a difference between predicate nominals and predicate adjectives (Baker, 2003; Szabó, 2015). For instance following Geach (1962) and Gupta (1980), Baker (2003) argues that nouns are the lexical category that have criteria of identity, which determine when something is the same F. For instance Baker holds that nouns like passenger and person have criteria of identity that determines when $a$ is the same passenger or the same person as $b$. Since the criteria of identity associated with them are distinct, $a$ might be the same person as $b$ without being the same passenger as $b$ (Baker, 2003: 102; Gupta, 1980: 23).

Taking nouns to have criteria of identity brings metaphysical and psychological baggage into a syntactic and semantic theory. Baker requires that criteria of identity are precise enough that passenger and person are distinguished. Presumably there are metaphysical distinctions between these categories, but should we think they are built into the semantics of our language? Are these criteria features that a formal semantic theory should be beholden to? I am wary about adding criteria of identity to a semantic theory. In the next section, I propose an account that avoids positing criteria of identity in semantics. The account I offer is in the tradition of taking nouns, as a lexical category, to be devices that purport to refer (Szabó, 2015). It formalizes ideas from Jesperson (1924/1951) 
and Wierzbicka (1986) that nouns involve categorizing into inductively potent kinds. Before developing the account, I consider and argue against non-semantic explanations for the differences between predicate nominals and predicate adjectives.

The distinction between predicate nominals and predict adjectives is robust, systematic, tied to lexicalized distinction, and affects what we take to have been communicated. This gives us evidence that the distinction falls within the target domain of a semantic theory. Yet, one might argue that while a complete theory of psychology or of communication ought to capture the difference, it does not require positing a semantic difference. Inferences from predicate nominals to judgements about persistence, stability, explanatoriness, and centrality to the subject's identity are not plausibly part of what is said (i.e., they are not components of the at-issue content). So, one might argue that they fall outside semantics proper and ought to be explained in other terms. Here I consider two alternative explanations — one psychological, the other pragmatic — and argue that both come up wanting.

First, one might argue the distinction ought to be explained by a psychological theory. To get a better feel for the idea, consider an analogy with typicality effects. Some instances of a category are taken to be more typical than others. For instance, sparrows are taken to be more typical members of the category bird. Penguins are taken to be less typical. Research has shown that people are quicker to categorize typical than atypical members (Rosch, et al., 1976). They also generalize more broadly from typical than atypical category members (Rips, 1975). While these findings show something about human psychology one could argue that they do not require anything from a semantic theory. Similarly, one might argue that the differences in the effects of predicate nominals and adjectives are likewise data to be explained by a psychological rather than semantic theory.

In the case at hand, we have seen that the lexical category of an expression makes a significant impact on people's judgments. We saw this felicity judgments for contrastive sentences, in the way conversational exchanges go, and in the availability of kind-denoting anaphors. Further, we 
saw that this holds even for completely novel nouns and adjectives. The data canvassed in $I$ require an explanation that gives a central role to lexical categories. If a psychological account is to get off the ground, there still needs to be some explanation for why we interpret cases like $1 \mathrm{a}$ and $1 \mathrm{~b}$ differently. For instance, to explain typicality effects one might appeal to observation rates. We are likely to have seen more birds that look like sparrows than like penguins. Or an explanation might be given in terms of features that are represented as typical of birds that sparrows have and penguins lack (e.g., the ability to fly). Explanations of this sort are not available for the cases at hand. This is made particularly salient as people have different judgments even about someone being said to be dax versus a dax. The difference in lexical category is what is relevant. A psychological account cannot be the full story. ${ }^{7}$

One might concede that the distinction between predicate adjectives and nominals is to be accounted for by a theory of language, but argue that the explanation ought to be given in terms of pragmatic mechanisms. The clearest route here is to argue that predicate nominals can violate Grice's Maxim of Manner (1975) and trigger an essentializing implicature. For example, a speaker who opts for 19 rather than 18 violates Manner by being prolix. In so doing she implicates something about the dish James made not being very good or not meeting her standards for a stew.

18. James made a stew.

19. James combined ingredients to approximate something you might call a stew.

Utterances with predicate nominals are (ever so slightly) less succinct than utterances with predicate adjectives. Given this, one could argue that utterances containing predicate nominals that have grammatical adjectival alternatives flout Manner and thereby elicit an implicature. A pragmatic account of the inferential difference could also be motivated by the conversational data from $I c$. These dialogues seemed to involve someone objecting to a way of phrasing something ("I wouldn't say...”). Exactly how the implicature from an added determiner elicits essentializing inferences

\footnotetext{
${ }^{7}$ I thank an anonymous referee for recommending I consider a purely psychological account and for suggesting the analogy with typicality effects.
} 
would need to be spelled out, and it is not clear to me how this would be done, but we do have some prima facie evidence for an explanation in terms of a violation of Manner.

To see why a pragmatic account along these lines comes up wanting, note again that the difference between predicate adjectives and nominals rests on a particular lexical item. When a particular lexical item makes a systematic difference to the import of utterances in which it is embedded, there is good reason to think that the difference should be explained by a semantic rather than merely pragmatic theory. Further, as we saw data from psychology reveal that labeling quite generally elicits strong inferences. This was the case even when the labeling condition (i.e., the nominal) was more succinct than the adjectival or verbal construction (as in the pair in 5). It also held for novel cases in which it was not clear to participants that there was an adjectival alternative (in 6). This should give us pause in trying to offer a pragmatic explanation.

An explanation based on flouting Manner also fails to adequately account for other data involving cancellation. Conversational implicatures are usually taken to be cancellable. Yet, judgments that predicate nominals categorize the subject and elicit judgments about further shared properties, stability, and so on are hard to cancel. ${ }^{8}$ For instance, suppose that a speaker is in a context in which a job candidate's sex is being discussed extensively. Someone might express frustration and say that the issue should be laid to rest and utter $20 \mathrm{a}$ or $20 \mathrm{~b}$.

20. a. ?? She's a female, but I don't think females share other properties or that being a member of the kind is explanatory.

b. ?? She's a female, but there is nothing more to being a female than being female. ${ }^{9}$

While I take it $20 \mathrm{~b}$ is more natural, both are odd, at least in part, because the first clauses strongly elicits the judgment that the speaker holds that females are an inductively potent kind and that membership is explanatory. Even though cancellation may not be impossible, it is not easy.

\footnotetext{
${ }^{8}$ Note that I am not arguing that a specific stereotype or negative valence cannot be cancelled. I take it these can be cancelled, as would be predicted on an essentialist view on which superficial properties, are not essential. Rather, my claim is that it is challenging for a speaker to cancel that there is a kind with stable membership, inferential potential, and so on. I return to a discussion of the sort of content I take essentializing inferences to have in III.

${ }^{9}$ I thank Matt Teichman for this suggestion.
} 
Given that conversational implicatures are cancellable, these data pose a problem for an implicature account. Cancellability has, however, been challenged as a general feature of conversational implicatures. Instead it has been argued that if a conversational implicature is at-issue, it is not cancellable, while if it is not at-issue, it is cancellable (van Kuppevelt, 1996; Rett, 2020). For instance, consider a pair involving scalar implicature (Rett, 2020):

21. A: Who passed some exams?

B: John. In fact, he passed all of them.

22. A: How many exams did John pass?

B: Some. \#In fact, he passed all of them.

The questions under discussion (i.e., QUDs, see Roberts, 1990) in 21 and 22 are different. They make different content at-issue since at-issue content is content that addresses a QUD. In 22 it is atissue whether John passed none, some, but not all, or all of the exams. In 21 it is not. The examples show that scalar implicature is cancellable only when it is not at-issue.

Suppose that sentences of the form ' $A$ is an $F$ conversationally implicated that $F$ s are an inductively potent kind with stable and explanatory membership. If the QUD is not addressing whether $F_{\mathrm{S}}$ are a kind or whether there is some shared essence $F_{\mathrm{S}}$ share or whether $A$ has the $F$ essence, the implicature should be cancellable.

23. A: Is Sodiq a queer?

$\mathrm{B}$ : Yes, Sodiq is a queer, \#although I don't think there is anything more to being a queer than being queer / \#although I don't think queers are a group that is explanatory or has further shared traits.

B's attempt to cancel the supposed implicature is not felicitous even when the content is not at-issue. A pragmatic story based on Manner cannot account for the full range of data. ${ }^{10}$

\section{A Semantics: Kinds and Presuppositions}

\footnotetext{
${ }^{10}$ I set aside accounts based on conventional implicature as they are more akin to semantic than pragmatic accounts and, therefore, not properly accounts that could be used to argue that the inferences from predicate nominals fall outside the domain of a semantic theory (Potts, 2005).
} 
We have seen that semantics ought to capture the difference between predicate nominals and predicate adjectives. I begin this section by considering a lexicalization strategy and arguing that it is not viable. I then sketch a psychologically motivated semantic view that captures the difference between predicate adjectives and nominals.

The data with which we began involve terms that are normatively-laden and politically fraught—like terms for racial and gender groups and appropriated slurs. ${ }^{11}$ Given these examples, one might think that the best way to explain the data is not by positing a systematic or compositional role for the indefinite article or indefinite singular NPs, but rather by positing distinct lexical items for 'a female' and 'a Black' and for any other predicate nominals from which essentializing inferences are drawn.

The productivity data canvassed in I provide some reason to think that this is not going to serve as a sufficient explanation. In the study reported there, we saw that even when presented with completely novel expressions (e.g., dax), adults were apt to think that categorization was more persistent and stable when a noun rather than adjective was used.

Additional data involving stage-level predicates and the insertion of an indefinite article provide more evidence that lexicalization cannot be a complete explanation. Stage-level predicates (be drunk, be tired) are predicates that apply to a subject for a period of time, but not necessarily at all times (Carlson, 1977). Stage-level predicates are contrasted with individual-level predicates, which, roughly, apply to an individual at every moment of its existence once they begin to truly apply to the individual. Being tall, knowing how to ride a bike, and the predicates used in sentences 1-4 are individuallevel predicates.

When stage-level predicates are combined with an indefinite article and modified by the -er suffix there is a shift in aspect from describing an event to describing a fixed state.

\footnotetext{
11 See Neufeld (2019) for arguments that slurs have an essentialist semantics and that this helps to explain why most slurs are nouns.
} 
24. a. Emmanuel is speaking French / is skiing.

b. Emmanuel is a French speaker / is a skier.

c. Emmanuel speaks French / skis.

25. a. George is drinking / is taking a test.

b. George is a drinker / is a test-taker.

c. George drinks / takes tests.

24a and 25a include stage-level predicates. They describe particular transitory episodes or events. In contrast, 24b and 25b label the subject and describe a state (rather than a transitory event) that involves a persistent feature of an individual. This is a systematic shift, rather than a feature that can be attributed to the meaning of some particular noun (e.g., skier). Note further, that while the interpretations of the $\mathrm{b}$ sentences are closer in meaning to the habituals in the c sentences, they are not equivalent. ${ }^{12}$ Three pieces of evidence support the claim. First, there are cases in which one can be an $\mathrm{F}$ without habitually $\mathrm{F}$-ing. For instance, one is a murderer even if one has committed a single murder. The predicate nominal can be true even when the habitual is false. Second, one can felicitously utter sentences with a habitual and a denial of the predicate nominal as in 26:

26. Emmanuel skis, but is not a skier.

Finally, as we saw in $I a$, research in developmental psychology shows that a person being said to do something often (or at least whenever they can) and being labeled with a predicate nominal support different judgments about stability and persistence. The lexicalization view should be rejected. The difference between predicate nominals and adjectives is robust and ought to be captured in a semantic theory in a systematic way.

Predicate nominals label or categorize. They say what the subject is. In contrast, adjectives ascribe properties that may or may not be long-standing or central to who the subject is. To capture these differences, I argue that predicate nominals involve attributing kind membership to an individual (or some individuals), whereas predicate adjectives involve individuals being ascribed a

\footnotetext{
12 The sentences in $24 \mathrm{c}$ have both a habitual and an ability interpretation. Those in $25 \mathrm{c}$ are much more likely to be interpreted as habituals (although if George is an infant the ability interpretation becomes more plausible). Here I focus on the habitual interpretation of these sentences.
} 
property (see Wierzbicka, 1986 for a similar view, without a formal implementation). Here I offer a semantic fragment that involves distinct compositionally derived semantic representations for sentences like 1-4. Predicate nominals attribute kind membership, while predicate adjectives ascribe a property. I then argue that kind-referring terms trigger a presupposition that explains our judgments about stability and explanatoriness.

I posit a domain of entities with two sorts_-individuals and kinds (Carlson, 1977; Link, 1983; Chierchia, 1998). Individuals are either atomic (e.g., Lola) or plural (Lola+Mohammed). Following Link (1983) the domain of individuals forms a complete atomic join semilattice. The join operator, + , forms plural individuals. It is defined on any atomic or plural individuals, $a, b$, so that $a$ $+b$ is the smallest plural individual composed of them. Kinds are a different sort. The join operator is not defined on them. Kinds have members, instances, or realizations. The membership relation is encoded in a version of Carlson's (1977) realization relation. ${ }^{13}$ The realization relation, $\mathrm{R}(x, k)$, expresses that $x$ is a realization of $k$. It is defined for any $x$ that is an atomic or plural individual and for any $k$ that is a kind. For instance, $\mathrm{R}$ (Samir, khuman) says that Samir is a realization of the kind human.

We now have the minimal resources needed to provide semantic analyses of our original examples in 1 . The logical form for $1 \mathrm{a}$ is $1 \mathrm{a}$ '.

1. a. Anna is female. a'. female(Anna)

To deliver this in a compositional way, I rely on standard semantic resources from Heim and Kratzer (1998). The semantic value of a name is an individual (27). Adjectives are function from entities to truth values (28) and the copula is taken to be semantically null (29).

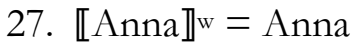

28. $\llbracket$ female $\rrbracket^{\mathrm{w}}=\lambda \mathrm{x} \in \mathrm{D}$. $\mathrm{x}$ is female in $\mathrm{w}$

29. (First Pass) $\llbracket \mathrm{be} \rrbracket \mathrm{w}=\varnothing$

\footnotetext{
13 In addition to individuals and kinds, Carlson (1977) posits stages of objects and kinds. The version of the realization relation I use here is Carlson's as modified by Krifka et al. (1995) to avoid an appeal to stages.
} 
These entries and the function application rule, deliver the correct semantics as shown in $1 \mathrm{a}$ ".

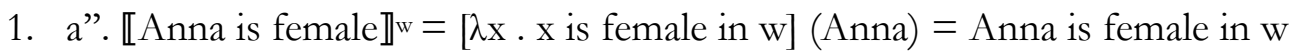

Recall that in standard theories, including Heim and Kratzer's, there is no difference between 1a and

1b. I have argued that predicate adjectives and predicate nominals are not semantically equivalent.

So, $1 \mathrm{~b}$ has to be given a distinct semantic value. The difference in the treatments is that while a simple property is predicated of an individual in $1 \mathrm{a}$, on the account offered here predicate nominals involve attributing kind membership to the subject. For instance, the predicate nominal in $1 \mathrm{~b}$ has $1 \mathrm{~b}$ ' as its logical form.

1. b. Anna is a female.

b'. R(Anna, kfemales)

To deliver this compositionally, the combination of the indefinite article and a count noun needs to have as one of its possible semantic values, a kind interpretation as in $30 . .^{14}$

30. $\llbracket a$ female $\rrbracket^{\mathrm{w}}=\mathrm{k}^{\text {females }}$

The semantic value of Anna is as stated in 27. Since both Anna and a female are of type $e$, the copula needs to have a semantic value that can combine these to deliver something of type $t$. To enable this I take the copula to be ambiguous between the null value given in 29 and the IS relation (Krifka et al., 1995: 86). The IS relation is a generalization of the identity relation and Carlson's realization relation. It is defined as as follows:

$$
\text { 31. } \operatorname{IS}(x, y)=_{\mathrm{df}}((x=y) \vee \mathrm{R}(x, y)) \cdot{ }^{15}
$$

\footnotetext{
14 Clearly this is not the only available interpretation of indefinite singulars. For instance, they can also have existential interpretations, as in 'A bird is chirping outside my window'. When the semantic fragment given here is expanded the entry for noun phrases of the form an F will need to be ambiguous between at least two values as in: \an $\mathrm{F} \rrbracket^{\mathrm{w}}=\mathrm{k}^{\mathrm{Fs}}$ or $\exists \mathrm{x}(\mathrm{Fx} \wedge \ldots)$. I take it that even in predicate position, predicate nominals do not always have kind interpretations. For instance, when a predicate nominal includes several modifiers as in 'Vivian is a tall funny mathematician' it is likely that there is no kind to which a tall funny mathematician can refer (See Chierchia, 1998; Prasada, et al., 2012; Markman, 1989; Ritchie \& Knobe, 2020). Therefore, a kind interpretation like that given for $1 \mathrm{~b}$ is unavailable and an alternative interpretation is needed. One route would be to rely on the existential disambiguation of the nominal.

15 Notice that for this relation to be well-typed kinds and individuals must both be of type $e$. In the semantics as sketched here both are of type $e$, they are of different sorts, but not different types. Thanks to an anonymous referee for noting that in this context.
} 
This gives us our revised semantic value for the copula in 29'.

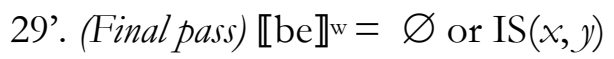

If $x$ and $y$ are both of the same sort (i.e., both individuals or both kinds) then $\operatorname{IS}(x, y)$ holds just in case they are identical. If $x$ is an individual and $y$ is a kind, it holds just in case $x$ is a realization of $y$. By making the entry for the copula the more general IS relation, we can avoid positing further ambiguity in order to provide analyses for sentences like 'Mark is Samuel' or 'groundhogs are woodchucks.' Since the subject in $1 \mathrm{~b}$ is an individual and the predicate nominal picks out a kind, the semantic value of $1 \mathrm{~b}$ is derived in a compositional way as in $1 \mathrm{~b}$ ". ${ }^{16}$

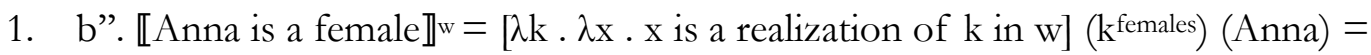
Anna is a realization of $\mathrm{k}^{\text {females }}$ in $\mathrm{w}$

So far I have provided distinct semantic analyses for predicate nominals and predicate adjectives. I have yet to explain why predicate nominals elicit essentialist thinking and have stronger inferential potential than their adjectival correlates. Before offering my account of essentializing inferences, I consider a potential worry for the account as offered thus far.

There is evidence that indefinite singular noun phrases cannot pick out kinds. If this is correct the entry in 30 cannot be one of the possible semantic values for a female. To see why some have thought this, notice the contrast between $32 \mathrm{a}$ and $32 \mathrm{~b}$.

32. a. Dinosaurs are extinct / widespread. b. *A dinosaur is extinct / widespread.

While the sentences with bare plurals in 32a are interpreted as being about kinds, those in 32b are marked (or must be interpreted as being about a particular species of dinosaur). Cohen (2004) argues that bare plurals and indefinite singulars also have different distributions in object position as in his $33 \mathrm{a}$ and $33 \mathrm{~b}$.

\footnotetext{
16 The account can straightforwardly generalize to sentences with plural subjects like 'Emma and Muska are females.' We simply need to add the entry for the bare plural as in: $\llbracket$ females $\rrbracket^{\mathrm{w}}=\mathrm{k}^{\text {females. }}$. Since the domain of individuals is closed under the join operator, the domain includes the plural individual Emma+Muska. The $\mathrm{R}$ relation is defined for atomic and plural individuals. So everything else proceeds just as in $1 \mathrm{~b}$ ”.
} 
33. a. Kimberly hates plays.

b. Kimberly hates a play.

While 33a has a generic interpretation-she hates plays in general-33b seems to have only an existential interpretation. "Which play does she hate?," you might ask. Given this and other data, ${ }^{17}$ some argue that indefinite singulars cannot denote kinds (e.g., Krifka et al., 1995; Cohen, 1999, 2004).

Luckily for the account I give here, other data pushes us to reconsider the view and suggests that indefinite singulars can indeed pick out kinds. First, consider variants of Cohen's examples in the pair below.

34. a. Kimberly hates melodramatic plays/ spicy curries / strong drinks. b. Kimberly hates a melodramatic play/ a spicy curry / a strong drink.

The contrast between the pairs here is far less striking. Both $34 \mathrm{a}$ and $34 \mathrm{~b}$ have easily accessible generic or kind-level interpretations.

Data involving inferences like in 35-37 provide further reason for us reconsider the view that indefinite singulars cannot denote kinds.

35. Emma is a female.

36. Muska is a female.

37. So, Emma and Muska are females.

Notice that 37 follows from 35 and 36 . When the subject expression is plural, a predicate nominal is expressed as a bare plural. There is consensus that bare plurals in English can denote kinds. This is the standard view for direct kind generics like in 32a (see Krifka, et al., 1995; Leslie \& Lerner, 2016; Sterken, 2017 for overviews). There is controversy about the correct semantics for characterizing generics like that expressed by 38, but some take these too to involve kind reference (Carlson, 1977; Liebesman 2011; Teichman, 2016).

38. Squirrels have tails.

\footnotetext{
${ }^{17}$ For instance, bare plurals are much more permissive in their ability to express generics than indefinite singulars. For instance, while "Rooms are square" has a clear generic interpretation, "A room is square" is likely to be interpreted existentially (see Lawler 1973; Burton-Roberts, 1977; Krifka et al. 1995; Cohen 1999, 2004; Greenberg, 2003).
} 
On all accounts bare plurals can denote kinds, so there is no reason to suppose that 37 could not be ascribing membership in a kind. And, since 37 follows from 35 and 36, we have further evidence that indefinite singulars in object position can also denote kinds. The number difference in the subject affects whether the predicate nominal is an indefinite singular or a bare plural, but it should not be taken to affect whether the predicate nominal picks out a kind. As is familiar from work on generics and kind-referring terms, the data is subtle. I certainly do not claim to have explained the distribution data showing when indefinite singulars can and cannot pick out kinds. I have, however, argued that there are instances in which indefinite singulars can pick out kinds. I conclude that the entry given in 30 is one possible semantic value for an indefinite singular construction. Next, I turn to explaining the inferential potential of predicate nominals.

I have argued that the difference between predicate adjectives and predicate nominals comes down to a difference in whether kind membership is attributed. To capture the robust inferential potential of predicate nominals, I argue that kind-denoting expressions trigger a presupposition that the kind has inductive potential and membership that is stable and explanatory. ${ }^{18}$

The most characteristic feature of presuppositions is their projection behavior (see Beaver \& Guerts, 2014 for an overview). For instance, when an expression that carries a presupposition that $p$ is embedded under negation or is in an interrogative, $p$ is presupposed by the negated sentence and by the question. For example, 39 is presupposed by $40 a-c$.

39. David used to raise goats.

40. a. David quit raising goats.

b. David did not quit raising goats.

c. Did David quit raising goats?

\footnotetext{
18 There is debate about whether presuppositions should be understood in pragmatic or semantic terms (see Beaver $\&$ Guerts, 2014 for an overview). Here I take the presupposition to be tied to lexical/sentential form rather than conversational context, but, as Simons (2003) argues, even on pragmatic views of presupposition a notion of sentence presupposition is often implicit.
} 
Similarly, the data considered in I provided evidence that something like 41 is taken for granted by 42a-c.

41. There is an inductively potent kind, females, with stable and explanatory membership.

42. a. Anna is a female.

b. Anna is not a female.

c. Is Anna a female?

A speaker uttering $42 \mathrm{a}-\mathrm{c}$ assumes that 41 is true and assumes that the hearer also takes it to be true (or will easily accommodate its truth). Conversational exchanges in which a hearer answering a question like $42 \mathrm{c}$ hedges, as we saw in the conversational exchange data in $I c$, give evidence that the content of 41 is not taken to be new information. Since presuppositions are usually taken to be backgrounded or taken for granted, it is plausible that the additional information predicate nominals carry is presuppositional.

Presuppositions are also difficult, although not always impossible, to felicitously cancel. We saw in section II that the possibility of cancelling inferences from predicate nominals is also limited. Notice that following up 42a with the denial of 41 has a ring of inconsistency. A denial of 41 followed by an assertion (perhaps prefaced by "so") of 42b sounds far more felicitous. Notice, however, that this patterns with examples that have been argued to involve local accommodation, as in 43 (see, e.g., Heim, 1983).

43. There is no King of France. So, the King of France will not be coming to your party. The data involving predicate nominals fits with data for other presupposition triggers. ${ }^{19}$

On the account developed here kind-denoting terms trigger a presupposition that there is a an inductively potent kind with stable and explanatory membership. This presupposition holds for kind-denoting terms in general. In some cases, including our examples in $1 \mathrm{~b}-4 \mathrm{~b}$, it is plausibly supported by the kind being represented as having an underlying causal biological essence (Gelman, 2003). In others, it could be supported by an evaluative or teleological essence (Newman \& Knobe,

\footnotetext{
${ }^{19}$ I thank an anonymous referee for suggesting this point.
} 
2019; Rose \& Nichols, 2020). And in yet other cases, the elements encoded in the presupposition might relate to structural features (Vasilyeva \& Lombrozo, 2020). The semantics given here is compatible with these and other views.

On the proffered account, specific traits or stereotypes are not posited as components of the presupposition. Rather it is general, as shown in 41. Any specific judgments one might draw from attributing kind membership_glamor, athleticism, stupidity_are not captured through semantics proper. Rather, they are to be captured through a theory of mental representation. ${ }^{20}$

Similarly, negative valence is not included as a component of the presupposition. While many essentializing inferences—including those elicited by our core set of examples — seem to be negative, I do not take this to be a semantic feature. Rather it is to be explained either by specific features that are connected to the kind (e.g., stupidity) or by the connection between categorization and dehumanization. Claims that presuppose that someone's behavior, aptitudes, and preferences are to be explained in terms of social kind membership can dehumanize and undermine the presumption that the subject is an agent (Neufeld, 2020; Smith, 2020). ${ }^{21}$ This is made more salient in our core examples given the fact that race, gender, and sexual orientation are aspects of identity that are intimately related to (if not constituted by) systems of structural oppression.

There are other predicate nominals that do not seem to elicit negative inferences. For instance, 44 includes a predicate nominal, but it is unlikely to be taken to imply something negative or dehumanizing.

\footnotetext{
20 There are various routes one might take to capture more specific properties and stereotypes that come to mind. Mental representations of kinds themselves might be structured and include some properties view principled connections (Prasada \& Dillingham, 2006, 2009). On an associationist account the specific thoughts that come to mind are based on associations between mental representations of more specific traits (e.g., NURTURING, UNINFORMED), other categories (e.g., MOTHER), or valence (Mandelbaum, 2017). On an inferentialist account one draws additional more specific inferences from other (unconscious) beliefs or attitudes one holds about a kind (Mandelbaum, 2016; Quilty-Dunn \& Mandelbaum, 2018).

21 Note that there is a striking difference between members of a group self-labeling and someone else labeling another person or group of people (e.g., "You are a queer" versus "I am a queer"). Labeling others might be dehumanizing and involve denial of agency in a way that self-labeling does not.
} 


\section{Felicia is an architect.}

The semantic account I offered above, holds for it too. 44 expresses that Felicia is a member of the

kind, architects. It triggers the presupposition that there is an inductively potent kind, architects, with stable and explanatory membership. As I argue in Ritchie (forthcoming), the lack of negative valence or dehumanization can be explained in part by the nature of social kinds and in part by our attitudes.

Members of social kinds like architects, professors, and point guards have reasonably welldefined roles. These roles are institutionally entrenched (e.g., they involve licensing exams) and their existence depends on social practices, beliefs, doctrines, and the like. That someone plays a particular role is explanatory and elicits the judgment that various other features hold of them given their membership in the kind (e.g., having knowledge of geometry, designing buildings, being obligated to ensure building code compliance). Kinds like racial, gender, and sexual orientations are different. They often appear to be natural. They are not closely tied to institutionalized roles. This contrast can partially explain the difference in negative valence. In both cases kinds are taken to be inductively potent, but for some kinds this is due to playing a role, for others it is taken to be biologically determined. In other cases difference in valence has to do with our attitudes towards particular kinds and their members. We tend to have negative attitudes towards some professions (e.g., politicians) and not others (e.g., doctors). Appeal to extra-semantic mental attitudes can again explain these inferential differences.

A theory involving presupposition can also account for why some utterances with predicate nominals sound strange. If a presupposition, $p$, is not already accepted or easily accommodated, a sentence that presupposes $p$ is infelicitous. For example, it would be odd to utter 40a if it is common knowledge that David never raised goats. Similarly, if it is not accepted that there is an inductively 
potent kind with stable and explanatory membership, use of a predicate nominal will sound strange. ${ }^{22}$

For instance, in contemporary American society, while a shared explanatory racial essence is often ascribed to those racialized as Black, it is less commonly held that there is a white racial essence. Similarly, while some take gay people to share an essence, the view that straight people share an essence that is causally explanatory is much less pervasive. This helps explain why utterances like 45 may sound less felicitous than $1 \mathrm{~b}-4 \mathrm{~b} .{ }^{23}$

45. ?? Karen is a white.

I claim that in contexts in which 45 sounds infelicitous, it is due to a presupposition failure. In that context it is not taken for granted or accommodated that there is an inductively potent kind, whites, with stable and explanatory membership. In other contexts, like one in which white supremacy and white ignorance are being discussed, an utterance of 45 may sound completely felicitous. In such contexts it is taken for granted that whites are a social kind.

Linguistic and psychological data support a theory that differentiates predicate adjectives and nominals. On the account argued for here, predicate nominals involve classifying individuals into kinds, while predicate adjectives fail to involve kind reference. I argued that kind-referring terms trigger a presupposition that an inductively potent kind exists and has stable and explanatory membership. This explains why nominals essentialize in ways adjectives do not.

While my concentration here has been adjectives and nouns in predicate position, this more narrow study contributes to the larger project of unifying work in formal semantics with psychological research on mental representation. I motivated the semantic account I offered here in part by setting my sights on a semantic theory that coheres with findings from psychology. In so

\footnotetext{
22 Teichman (2016) makes a related claim to support the infelicity of certain predicates in the subject position of generic generalizations (e.g., the infelicity of "Toppings on this pizza are vegetarian"). His explanation relies on cohesive sortal predicates. My argument, in contrast, explains the data in terms of mental representations.

23 I mean 'felicitous' here to rely only on linguistic grounds. All of $1 \mathrm{~b}-4 \mathrm{~b}$ sound grammatical and are semantically interpretable. I do not mean felicitous in a moral or other deontic sense.
} 
doing, I argued that nouns refer to kinds more often than semanticists have assumed. The account developed here also opens new avenues to consider when inquiring into the psychological underpinnings of presuppositions.

Inquiry into essentializing inferences positions us at the nexus of socially-informed theories of mind and language. It forces us to confront the ways our cognitive architecture and social dispositions interface with linguistic form and points to new paths forward in understanding how we think, talk, and draw inferences about our world.

\section{Acknowledgements}

Support for this project was provided by a PSC-CUNY Award, jointly funded by The Professional Staff Congress and The City University of New York and from research funds from the University of California, Irvine. Versions of this paper were presented at the University of Minnesota Feminist Philosophy and Formal Logic Workshop, PhLiP, the Meaning and Reality in Social Context Conference at Academia Sinica in Taipei, and Philosophy of Language in Lima. I thank the audiences for useful feedback. In particular thanks are owed to Derek Anderson, Chris Barker, Roy Cook, Alex Grzankowski, Daniel Harris, Eric Mandelbaum, Sandeep Prasada, Craige Roberts, Jessica Rett, Gillian Russell, Adam Sennet, Yael Sharvit, Zoltán Szabó, Jack Spencer, Matthew Teichman, Yu Izumi and Jack Woods for comments and helpful discussion. I thank Matt Lindauer and Alexander Noyes for guidance on running an online study. Finally, special thanks to Josh Knobe for his feedback and for his support in running and analyzing the data from the study reported here.

\section{Works Cited}

Baker, M. (2003). Lexical Categories: Verbs, Nouns, and Adjectives. Cambridge: Cambridge University Press.

Beaver, D. I. and Geurts, B., "Presupposition", The Stanford Encyclopedia of Philosophy (Winter 2014 Edition), Edward N. Zalta (ed.), URL = <https://plato.stanford.edu/archives/win2014/entries/ presupposition/>.

Bigler, R. S. and Liben, L. S. (2007) Developmental Intergroup Theory: Explaining and Reducing Chidren's Social Stereotyping and Prejudice. Current Directions in Psychological Science. 16 (3): 162-166.

Burton-Roberts, N. (1977). Generic sentences and analyticity. Studies in Language 1: 155-196.

Cappelen, H. (2018). Fixing Language: An Essay on Conceptual Engineering. Oxford: Oxford University Press. 
Carlson, G. N. (1977). Reference to Kinds in English. Ph.D. thesis, University of Massachusetts, Amherst.

Carnaghi, A., Maass, A., et al. (2008). 'Nomina Sunt Omina: On the inductive potential of nouns and adjectives in person perception.' Journal of Personality and Social Psychology 94: 839-859.

Chaigneau, S., \& Barsalou, L. (2008). The Role of Function in Categories. Theoria Et Historia Scientiarum, 8(1), 33-52.

Chierchia, G. (1995). Individual Level Predicates as Inherent Generics. In Carlson, G. and F.J. Pelletier (eds.) The Generic Book, Chicago: Chicago University Press: 176-224.

Cohen, A. (2004). Generics and Mental Representations. Linguistics and Philosophy 27: 529-556.

Cohen, A. (1999). On the Generic Use of Indefinite Singulars. Journal of Semantics, 18(3), 183-209.

Del Pinal, G. \& Reuter, K. (2017). Dual Character Concepts in Social Cognition: Commitments and the Normative Dimension of Conceptual Representation. Cognitive Science 41 (S3):477-501.

von Fintel, K. and Heim, I. (2011). Intensional Semantics. Lecture Notes.

Geach, P. (1962). Reference and Generality. Ithaca: Cornell University Press.

Gelman, S. A. (2003). The Essential Child: Origins of Essentialism in Everyday Thought: Oxford University Press, USA.

Gelman, S. A. (2004). Psychological essentialism in children. Trends in Cognitive Sciences 8 (9): 404-409.

Gelman, S. A. and Coley, J. D. (1990). The Importance of knowing a dodo is a bird. Categories and inferences in 2-year-old children. Developmental Psychology. 26: 796-804.

Gelman, S. A., \& Heyman, G. D. (1999). Carrot-Eaters and Creature-Believers: The Effects of Lexicalization on Children's Inferences About Social Categories. Psychological Science, 10(6), 489-493.

Gelman, S. A., \& Markman, E. M. (1987). Young children's inductions from natural kinds: The role of categories and appearances. Child Development, 58, 1532-1541.

Graf, S., Bilewicz, M., Finell, E. and Geschke, D. (2013). Nouns Cut slices: Effects of Linguistic Forms on Intergroup Bias. Journal of Language and Social Psychology, 32 (1): 62-83.

Graham, S. A., Kilbreath, C. S. \& Welder, A. N. (2004) Thirteen-month-olds rely on shared labels and shape similarity for inductive inferences. Child Development 75, 409-427.

Grice, P. (1975). Logic and Conversation. In Maite Ezcurdia \& Robert J. Stainton (eds.), The Semantics-Pragmatics Boundary in Philosophy. Broadview Press. 47-59.

Greenberg, Y. (2003). Manifestations of Genericity. Doctoral dissertation. Bar Ilan University. Published in "Outstanding Dissertations in Linguistics" Series. New York: Routledge. 
Gupta, A. (1980). The Logic of Common Nouns: An Investigation in Quantified Modal Logic. New Haven and London: Yale University Press.

Haslanger, S. (2000). Gender and Race: (What) are They? (What) Do We Want Them To Be?. Noûs 34: 31-55.

Heim, I. (1983). On the projection problem for presuppositions. West Coast Conference on Formal Linguistics 2: 114-125.

Heim, I. and Kratzer, A. (1998). Semantics in Generative Grammar. Malden, MA: Blackwell.

James, W. (1902/2012). The Varieties of Religious Experience. Renaissance Classics.

Jaswal, V. K. and Markman, E. M. (2002). Children's acceptance and use of unexpected category labels to draw non-obvious inferences. In Proceedings of the 24th Annual Conference of the Cognitive Science Society (Gray, W. and Schunn, C. eds), pp. 500-505, Erlbaum.

Jespersen, O. (1924/1951). The Philosophy of Grammar. London: George Allen \& Unwin LTD.

Keil, F. C. (1989). Concepts, kinds, and cognitive development. Cambridge, MA: MIT Press.

Krifka, M., Pelletier, F.J., Carlson, G. N., ter Meulen, A., Chierchia, G., \& Link, G. (1995). Genericity: An Introduction. In: G. Carlson \& F.J. Pelletier (eds.), The Generic Book. The University of Chicago Press.

van Kuppevelt, J. (1996). Inferring from topics: Implicatures as Topic-Dependent Inferences. Linguistics and Philosophy, 19: 393-443.

Lawler, J. (1972) Generic to a Fault. In Papers from the 8th Regional Meeting, Chicago Linguistic Society (CLS 8), Chicago: Chicago Linguistic Society, pp. 247-258.

Leslie, S.-J. (2013). Essence and Natural Kinds: When Science Meets Preschooler Intuition. Oxford Studies in Epistemology, 4, 108-165.

Leslie, S.-J. (2015). "Hillary Clinton is the Only Man in the Obama Administration": Dual Character Concepts, Generics, and Gender. Analytic Philosophy 56 (2):111-141.

Leslie, S.-J. and Lerner, A. (2016) "Generic Generalizations", The Stanford Encyclopedia of Philosophy (Winter 2016 Edition), Edward N. Zalta (ed.), URL = <https://plato.stanford.edu/ archives/win2016/entries/generics/>.

Liebesman, D. (2011). Simple Generics. Nô̂s 45(3): 409-442.

Link, G. (1983). The Logical Analysis of Plural and Mass Nouns: A Lattice Theoretic Approach. In R. Bäuerle, C. Schwarze and A. von Stechow (eds.), Meaning, Use and Interpretation of Language. Berlin: de Gruyter.

Mandelbaum, E. (2017). Associationist Theories of Thought. In The Stanford Encyclopedia of Philosophy (Summer 2017 Edition), Edward N. Zalta (ed.), URL = <https://plato.stanford.edu/ archives/sum2017/entries/associationist-thought/>. 
Mandelbaum, E. (2016). Attitude, Inference, Association: On the Propositional Structure of Implicit Bias. Noûs 50 (3): 629-658.

Markman, E. (1989). Categorization and Naming in Children: Problems of Induction. Cambridge, MA: MIT Press.

Medin , D. L. , \& Ortony , A. (1989 ). Psychological essentialism. In S. Vosniadou \& A. Ortony (eds), Similarity and analogical reasoning (pp. 179-195). New York: Cambridge University Press.

Montague, R. (1973). The Proper Treatment of Quantification in Ordinary English. In J. Hintikka, J. Moravcsik, and P. Suppes (eds.), Approaches to Natural Language, Reidel, Dordrecht.

Newman, G. \& Knobe, J. (2019). The essence of essentialism. Mind and Language 34 (5):585-605.

Neufeld, E. (2020). Pornography and Dehumanization: The Essentialist Dimension. Australasian Journal of Philosopby DOI: 10.1080/00048402.2019.1700291.

Neufeld, E. (2019). An Essentialist Theory of the Meaning of Slurs. Philosophers' Imprint 19(35): 1-29.

Noyes, A., \& Dunham, Y. (2019, April 16). Separating kindhood from naturalness: Kinds are diverse in causal structure. https://doi.org/10.31234/osf.io/q3zg5

Quine, W. V. O. (1960). Word and Object. Cambridge, MA: MIT Press.

Quilty-Dunn, J. and Mandelbaum, E. (2018). Inferential Transitions. Australasian Journal of Philosophy 96(3), 532-547.

Partee, B. (2002/1986). Noun Phrase Interpretation and Type-Shifting Principles. In P. Portner and B. Parter (eds.), Formal Semantics: The Essential Readings, Blackwell.

Prasada, S., Hennefield, L., \& Otap, D. (2012). Conceptual and Linguistic Representations of Kinds and Classes. Cognitive Science 36: 1224-1250.

Prasada, S. \& Dillingham, E. M. (2009). Representation of principled connections: A window onto the formal aspect of common sense conception. Cognitive Science, 33, 401-448.

Prasada, S. \& Dillingham, E. M. (2006). Principled and statistical connections in common sense conception. Cognition, 99, 73-112.

Potts, C. (2005). The Logic of Conventional Implicatures. Oxford: Oxford University Press.

Rett, J. (2020). Manner implicatures and how to spot them.International Review of Pragmatics 12: 44-79.

Rips, L. J. (1975). Inductive judgments about natural categories. Journal of Verbal Learning \& Verbal Behavior 14, 665-681.

Ritchie, K. (forthcoming). Essentializing Language and the Prospects for Ameliorative Projects. Ethics. 
Ritchie, K. \& Knobe, J. (2020). Kindhood and Essentialism: Evidence from Language. In M. Rhodes (ed.) Advances in Child Development and Behavior-The Development of Social Essentialism (Vol. 59, pp. 133-165).

Roberts, C. (2005). Pronouns as Definites. In M. Reimer \& A. Bezuidenhout (Eds.) Descriptions and Beyond, Oxford University Press.

Roberts, Craige. (1990). Modal Subordination, Anaphora, and Distributivity. Garland Press.

Rosch, E., Simpson, C., \& Miller, R. S. (1976). Structural bases of typicality effects. Journal of Experimental Psychology: Human Perception and Performance, 2(4), 491-502.

Rose, D. \& Nichols, S. (2020). Teleological Essentialism: Generalized. Cognitive Science 44 (3).

Rothbart, M. \& Taylor, M. (1992). Category labels and social reality: Do we view social categories as natural kinds? In G. R. Semin \& K. Fiedler (Eds.), Language, interaction and social cognition (pp. 11-36). London: Sage.

Simons, M. (2003). Presupposition and Accommodation: Understanding the Stalnakerian Picture. Philosophical Studies 112: 251-278.

Smith, D. L. (2020). On Inbumanity: Debumanization and How to Resist It. New York, NY: Oxford University Press.

Sterken, R. K. (2017). The Meaning of Generics. Philosophy Compass 12 (8).

Szabó, Z. G. (2015). Major Parts of Speech. Erkenntnis 80 (1):3-29.

Teichman, M. (2016). The Sophisticated Kind Theory. Inquiry: An Interdisciplinary Journal of Philosophy:1-47.

Vasilyeva, N. \& Lombrozo, T. (2020). Structural Thinking about Social Categories: Evidence from Formal Explanations, Generics, and Generalization. Cognition. 204: 1-14.

Walton, G. M., \& Banaji, M. R. (2004). Being What You Say: The Effect of Essentialist Linguistic Labels on Preferences. Social Cognition 22(2): 193-213.

Waxman, S. R. (1990). Linguistic Bias and the Establishment of Conceptual Hierarchies: Evidence from Preschool Children. Cognitive Development 5: 123-150.

Webber, B. L. (1978) A Formal Approach to Discourse Anaphora. Bolt Beranek and Newman Report No. 3761. Reprinted as Webber, B. L. (1979) A Formal Approach to Discourse Anaphora. Garland Publishing, New York.

Wierzbicka, A. (1986). What's in a noun? (Or: How do nouns differ in meaning from adjectives?). Studies in Language, 10, 353-389. 